\title{
PATTERNING OF SELF-ASSEMBLED MONOLAYERS (SAMS)
}

\author{
Michal URBÁNEK, Pavel URBÁNEK, Michal MACHOVSKÝ, Ivo KUŘITKA
}

Centre of Polymer Systems, Tomas Bata University in Zlin, Czech Republic, EU, murbanek@utb.cz https://doi.org/10.37904/nanocon.2019.8592

\begin{abstract}
Self-assembled monolayers (SAMs) has recently received much attention because of their wide range in applications such as layers in biosensors, electronic active layers or interlayers in organic electronic devices like organic light emitting diodes (OLEDs), organic photovoltaics (OPVs), organic thin film transistors (OTFTs). Photolithography is a basic and long established technique used in the preparation of processors and other electronic components. This paper deals with patterning of self-assembled monolayers prepared on gold and silver layers using photolithography. Firstly, the prepared self-assembled monolayers were characterized by scanning electron microscopy (SEM), atomic force microscopy (AFM) and Fourier-transform infrared spectroscopy (FTIR). Subsequently testing patterns according to the resolution chart test were exposed by UV lithography. These prepared patterns were characterized by optical microscopy, atomic force microscopy (AFM) and scanning electron microscopy (SEM).
\end{abstract}

Keywords: Self-assembled monolayers, photolithography, SEM, AFM, FTIR, magnetron sputtering

\section{INTRODUCTION}

The self-assembled monolayers (SAMs), which were discovered about 30 years ago, currently offer a wide range of applications in micro and nanoelectronics, printed electronics on flexible substrates, various types of sensors, biosensors and, above all, active intermediate layers for organic light emitting diodes (OLEDs) and organic photovoltaics (OPVs) [1]. Thus, spontaneously formed monolayers can provide the necessary monolayer properties in the preparation of various functional structures. Alkanethiols are often used for the preparation of the layers [2,3], when the molecules of material are organized on the metal surface (predominantly noble metals such as gold or silver) in a crystalline or semi-crystalline structure $[4,5]$. Various structures with defined use can be created on the resulting layer. One of the suitable, reliable and wellestablished methods useful for this purpose is UV photolithography [6]. SAMs (Figure 1) will form a resist-like surface on a suitable metal layer, and since alkanethiols are UV-sensitive, the prepared layer serves as a resist through which it is possible to treat and form functional structures on the metal surface below the selforganized layer.

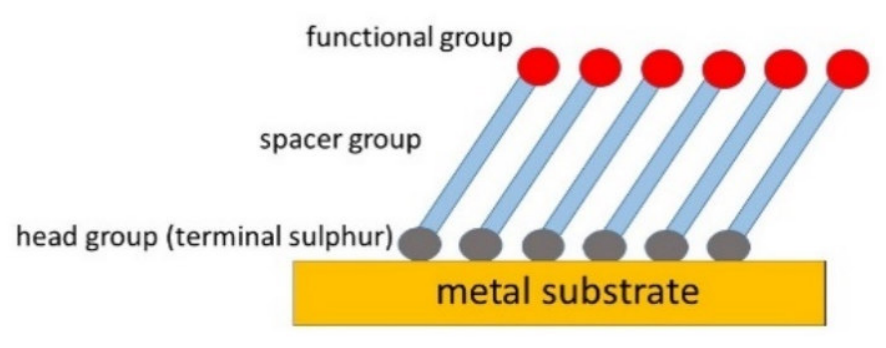

Figure 1 Self assembled monolayer

\section{PREPARATION OF MONOLAYERS}

1-octadecanthiol (ODT, Sigma Aldrich, 98\%) from the group of alkanethiols was used for prepare of selfassembled monolayers. The monolayers grew on silicon substrates coated with gold or silver. The metal layers 
on silicon were sputtered by magnetron sputtering, the thickness of gold layer for the preparation of ODT layers was $20 \mathrm{~nm}$, and the thickness of silver layer was $15 \mathrm{~nm}$. $10 \mathrm{mM}$ solution of ODT in isopropanol was used for layer growth. The organization of molecules took 6 hours and the final layers were baked at $50^{\circ} \mathrm{C}$ for 12 hours.

\section{CHARACTERIZATION METHODS}

FTIR spectra of thin layers were investigated by FTIR spectrometer 66700 from Nicolet - ThermoScientific (Figure 2). The presence of asymmetric mode $\mathrm{CH}_{2}$ at $2917.51 \mathrm{~cm}^{-1}$, symmetric mode $\mathrm{CH}_{2}$ at $2848.16 \mathrm{~cm}^{-1}$ and $\mathrm{CH}_{3}$ stretching mode at $2958.60 \mathrm{~cm}^{-1}$ indicates well organized monolayer.

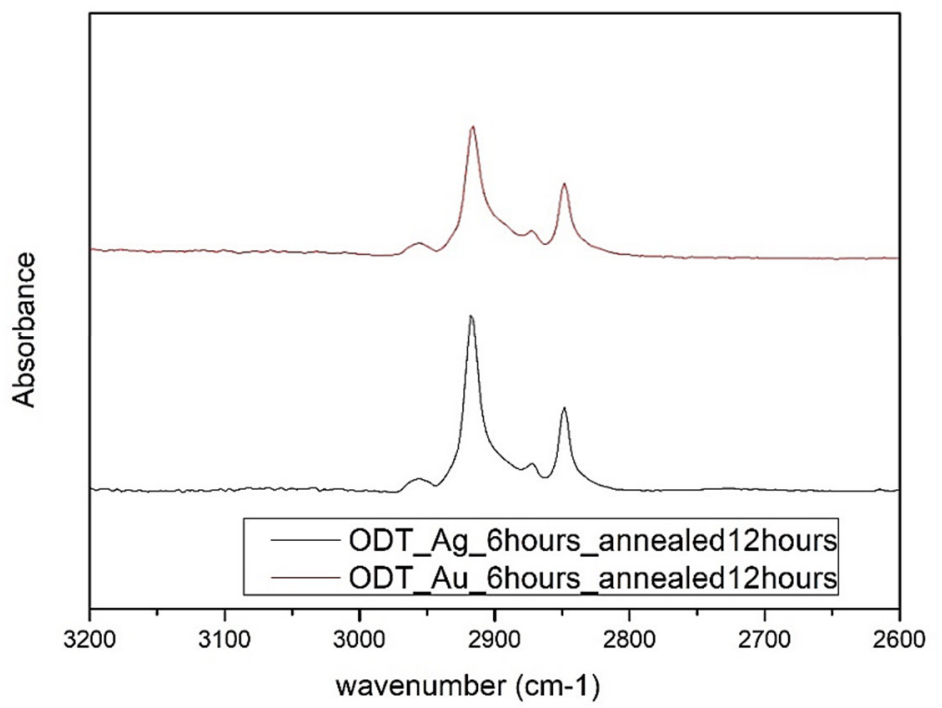

Figure 2 FTIR spectra of prepared monolayer of 1-Octadecanthiol $(\mathrm{CH} 3(\mathrm{CH} 2) 17-\mathrm{SH})$

Characterization of prepared monolayers was done by scanning electron microscope Nova NanoSEM 450 (FEI) with Schottky field emission electron source operated at acceleration voltage $5 \mathrm{kV}$. The images of the prepared layers show that the layer prepared on the silver surface shows bigger defects than the layer prepared on gold (Figure 3).

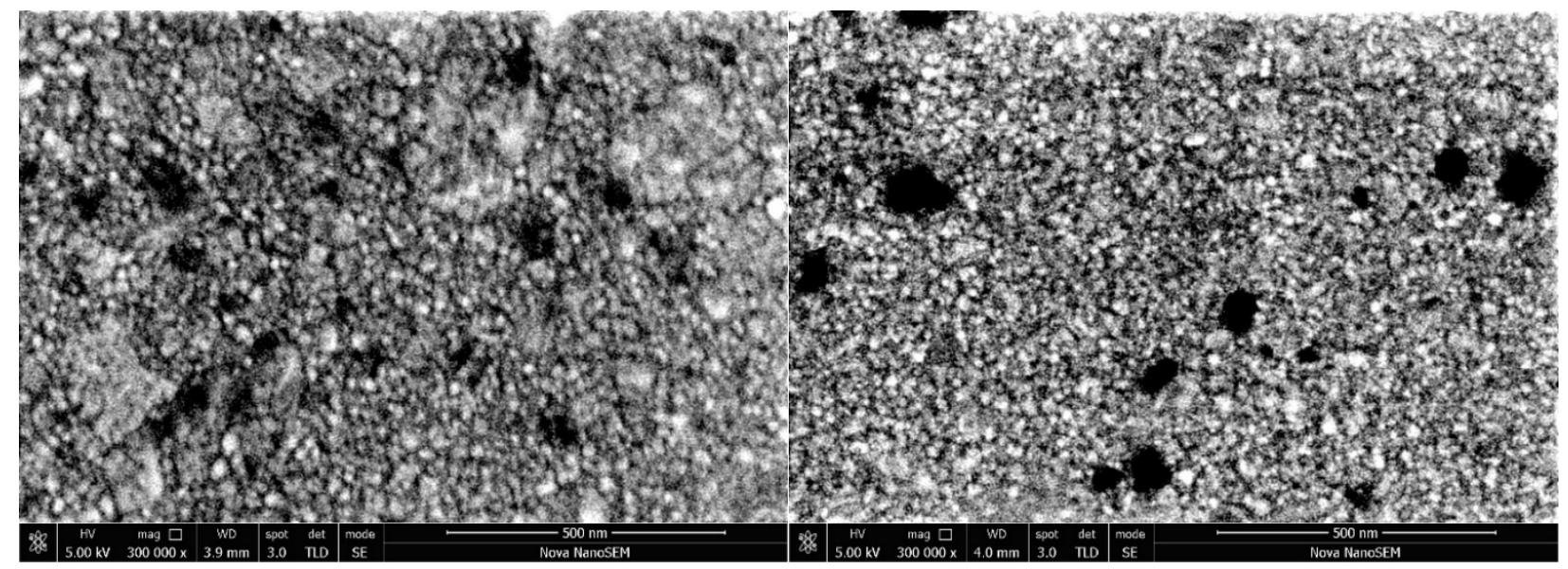

Figure 3 SEM images of prepared ODT monolayer left) silver substrate, right) gold substrate

The AFM images can be seen, the images of the prepared monolayers were taken by atomic force microscope Dimension ICON (Figure 4). 

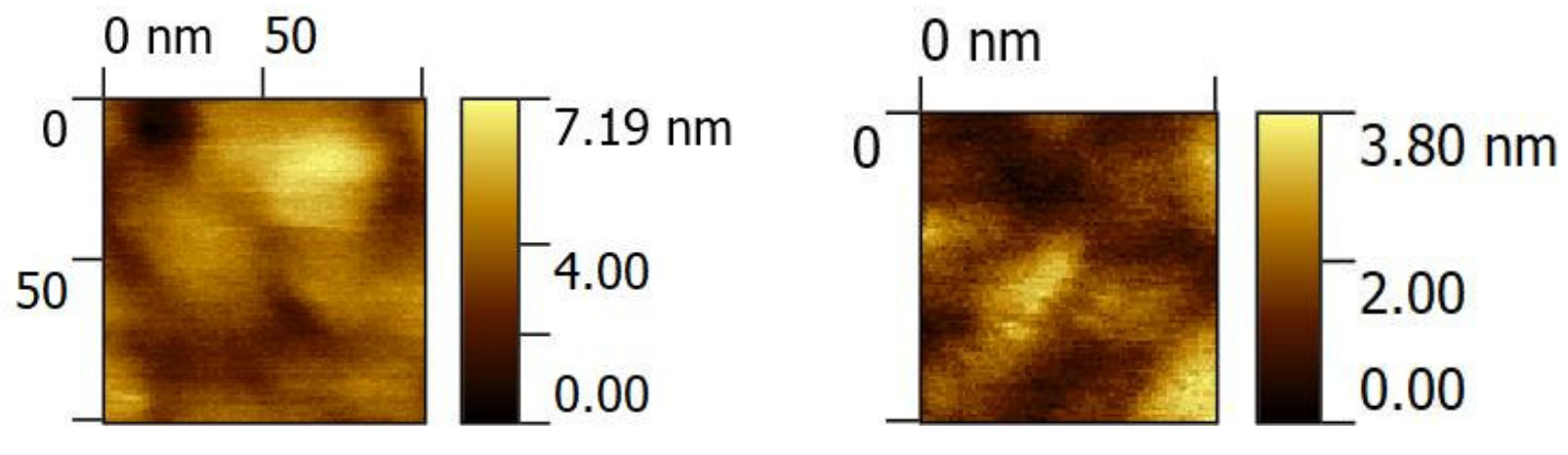

Figure 4 AFM images of prepared ODT monolayer left) silver substrate, right) gold substrate (scan size $100 \times 100 \mathrm{~nm}$ )

\section{UV PHOTOLITHOGRAPHY AND RESULTS}

Testing pattern was designed according to the USAF 1951 resolution test chart extended by star pattern (Figure 5). The exposure was carried out by Phillips mercury UV lamp $400 \mathrm{~W}$ for 20 minutes because of needs to achieve proper oxidation of layer. The development process was done by wet way in isopropanol for 30 seconds. The temperature of developer was at room temperature $-22.5^{\circ} \mathrm{C}$. Then the samples were rinsed in isopropanol and deionized water.

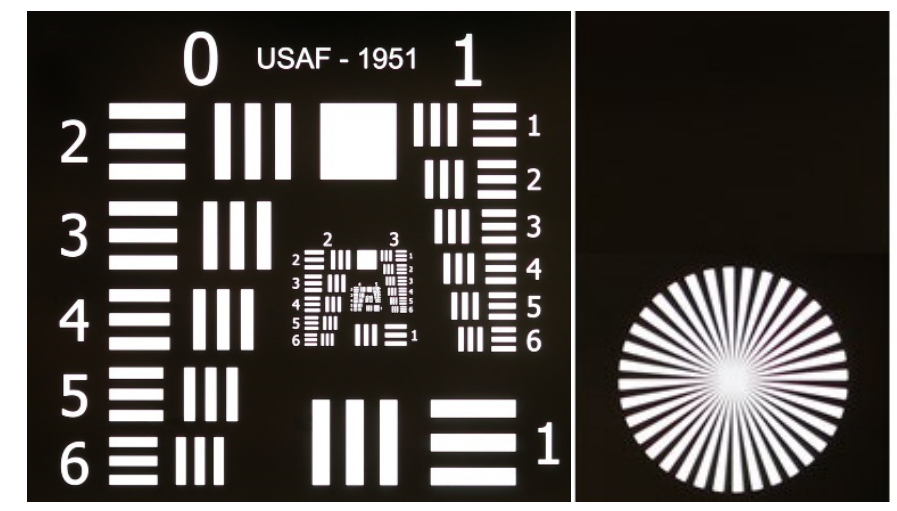

Figure 5 Exposure test design

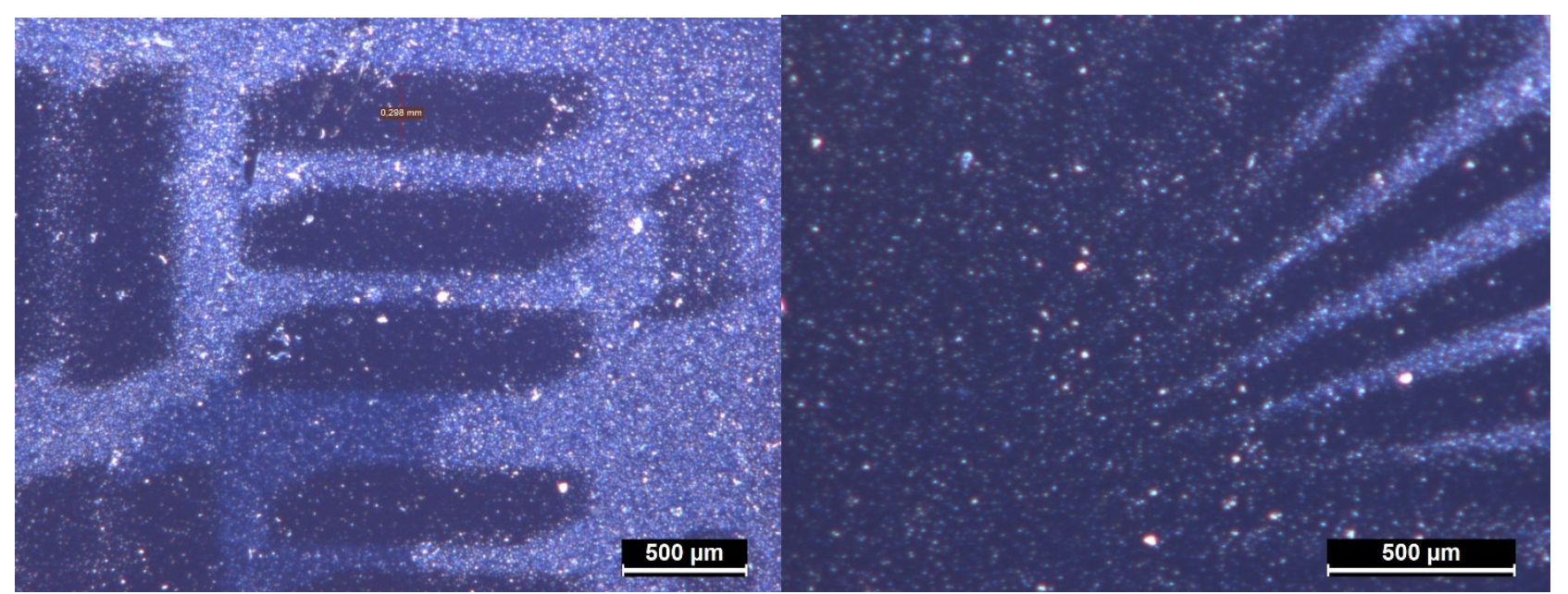

Figure 6 Testing element 1-1 from USAF 1951 test (left) and part of star motif (right) 
After development the structures were observed by optical microscopy Leica DVM 2500 (Figure 6). The dimension of line was determined in the element 1-1 of USAF test. The determined width of line is $298 \mu \mathrm{m}$ compared to the designed width of $250 \mu \mathrm{m}$.

The exposed and developed structures were also observed by scanning electron microscope (Figure 7).

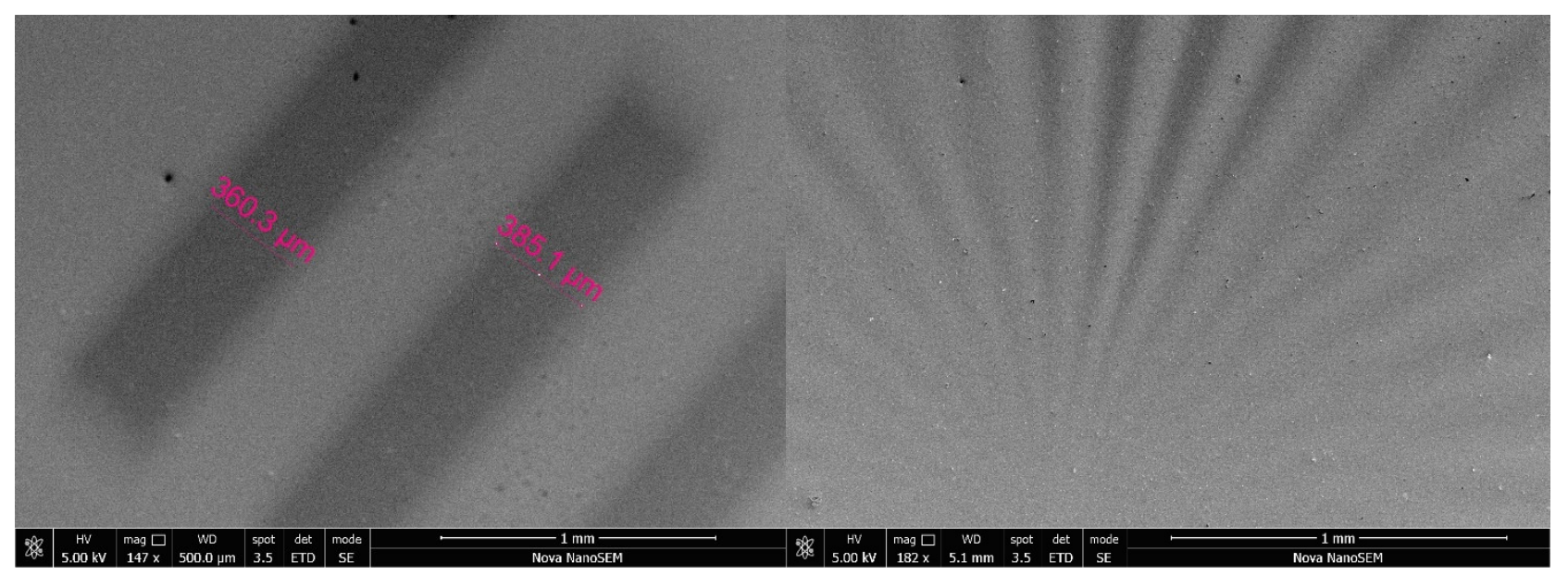

Figure 7 Testing element 0-4 from USAF 1951 test (left) and part of star motif (right).

The measured width of lines was $360 \mu \mathrm{m}$ respectively $385 \mu \mathrm{m}$ in comparison with designed width of $353.55 \mu \mathrm{m}$.

The exposed pattern was measured by atomic force microscopy (Figure 8). There is visible difference between exposed and non-exposed area but no sharp border.

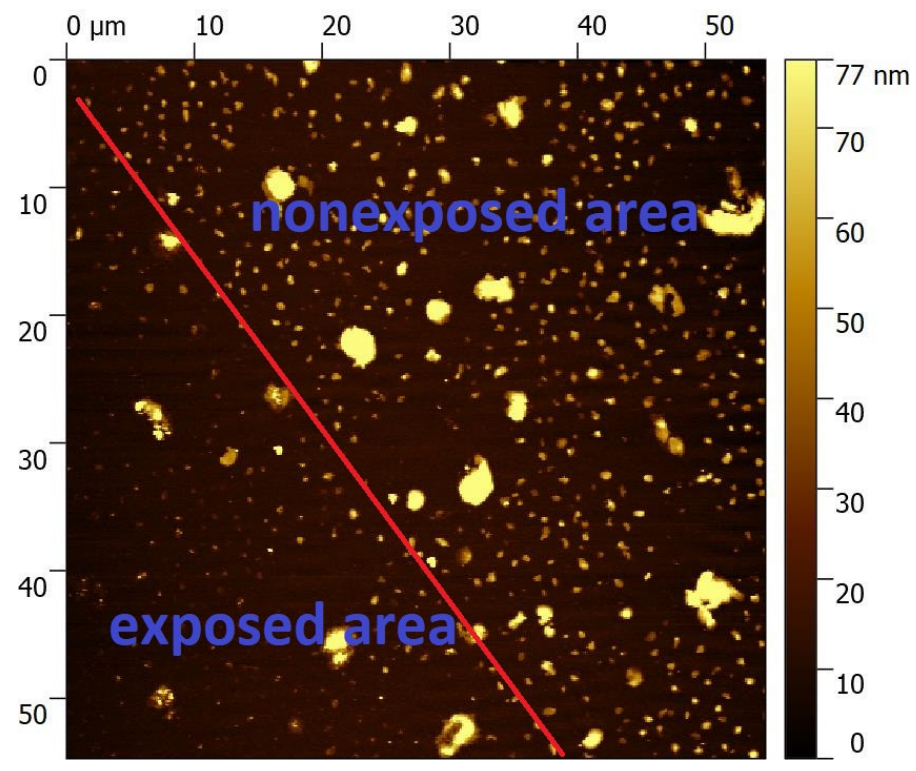

Figure 8 AFM image of border between exposed and non-exposed areas.

\section{CONCLUSION}

We successfully patterned self-assembled monolayer organized from 1-octadecanthiol. The self-assembled monolayers were prepared on silver and gold surface. The prepared monolayers were characterized by scanning electron microscopy, atomic force microscopy and Fourier-transform infrared spectroscopy. ODT 
monolayers were patterned by UV lithography and exposed patterns were observed and evaluated by optical microscopy, atomic force microscopy and scanning electron microscopy, the linewidths of exposed structures were determined from the measurements.

\section{ACKNOWLEDGEMENTS}

This work was supported by the Ministry of Education, Youth and Sports of the Czech Republic Program NPU I (LO1504).

This article was written with the support of Operational Program Research and Development for Innovations co-funded by the European Regional Development Fund (ERDF) and national budget of the Czech Republic, within the framework of the project CPS - strengthening research capacity

(reg. number: CZ.1.05/2.1.00/19.0409).

\section{REFERENCES}

[1] KE X. and SHUSEN X., Self-assembled molecular devices: a minireview, Instrumentation Science \& Technology, 2019, pp. 1-26, Taylor \& Francis, https://doi.org/10.1080/10739149.2019.1660182.

[2] DUBOIS, L. H. and NUZZO, R. G., Synthesis, Structure, and Properties of Model Organic Surfaces, Annual Review of Physical Chemistry, 1992, vol. 43, No. 1, pp. 437- 463, https://doi.org/10.1146/annurev.pc.43.100192.002253.

[3] BAIN, C. D., EVALL, J. and WHITESIDES, G. M, Formation of monolayers by the coadsorption of thiols on gold: variation in the head group, tail group, and solvent, J. Am. Chem. Soc., 1989, vol. 111, No. 18, pp. 7155-7164. https://doi.org/10.1021/ja00200a039.

[4] YELIZ, G., Aromatic versus aliphatic thiols on Au (111) surface: a DFT exploration of adsorption registry and electronic structure, Molecular Simulation, 2019, pp. 1-11, Taylor \& Francis, https://doi.org/10.1080/08927022.2019.1663844.

[5] AHN, J., SHI, S., VANNATTER, B. and QIN, D., Comparative Study of the Adsorption of Thiol and Isocyanide Molecules on a Silver Surface by in Situ Surface-Enhanced Raman Scattering, The Journal of Physical Chemistry C, 2019, vol. 123, No. 35, pp. 21571-21580, https://doi.org/10.1021/acs.jpcc.9b05383.

[6] URBÁNEK M. et al., Photolithography on Flexible Substrates, In Proceedings of Nanocon 2017, 9th International Conference on NANOCON, Oct 18-20, 2017, Brno, TANGER Ltd: Ostrava, 2018, pp. 914-917, ISBN 978-8087294-81-9. 